\title{
RESEARCH-IN-BRIEF
}

\section{Refining the Response-Frequency Measure of Media Habit - The role of time pressure}

\author{
Weiterentwicklung der Response-Frequency Measure \\ of Media Habit - Die Bedeutung von Zeitdruck \\ bei der Durchführung der Messung
}

Anna Schnauber-Stockmann \& Teresa K. Naab 
Anna Schnauber-Stockmann (Dr.), Department of Communication, University of Mainz, Jakob-Welder-Weg 12, 55099 Mainz, Germany; Contact: anna.schnauber-stockmann(at) uni-mainz.de

Teresa K. Naab (Dr.), Department of Media, Knowledge and Communication, University of Augsburg, Universitaetsstrasse 10, 86159 Augsburg, Germany. Contact: teresa.naab(at)phil. uni-augsburg.de 


\title{
Refining the Response-Frequency Measure of Media Habit - The role of time pressure
}

\author{
Weiterentwicklung der Response-Frequency Measure \\ of Media Habit - die Bedeutung von Zeitdruck \\ bei der Durchführung der Messung
}

Anna Schnauber-Stockmann \& Teresa K. Naab

\begin{abstract}
Media habits attract growing attention in communication research. Therefore, valid measures of habit strength are needed. The response-frequency measure of media habit (RFMMH) provides an implicit approach. It does not rely on retrospective self-reports of the habitual character of a behavior. Participants are presented with vignettes referring to various goal situations and choose under time pressure script-based which media device they would use in the respective situation. Choosing the same device across the different goal situations indicates strong general habits. The present paper refines the RFMMH by testing different time pressure levels in a heterogeneous sample to identify the ideal amount of time pressure.
\end{abstract}

Keywords: Response-frequency measure, media choice, habit, implicit measure

Zusammenfassung: Mediengewohnheiten finden in der Kommunikationswissenschaft immer mehr Beachtung. Deshalb bedarf es valider Messinstrumente zur Erfassung von Gewohnheitsstärke. Mit der Response-Frequency Measure of Media Habit (RFMMH) existiert ein Messinstrument, das Gewohnheitsstärke implizit, das heißt ohne Selbsteinschätzung des Gewohnheitscharakters, misst. Befragte werden mit verschiedenen Situationsbeschreibungen konfrontiert und wählen unter Zeitdruck und damit skriptbasiert die Mediengattung aus, die sie in der jeweiligen Situation nutzen würden. Je häufiger sie über die verschiedenen Situationen hinweg dieselbe Mediengattung wählen, desto stärker ist ihre diesbezügliche allgemeine Gewohnheit. Die vorliegende Studie testet verschiedene Zeitdruckbedingungen an einer heterogenen Stichprobe, um das passende Maß an Zeitdruck in der RFMMH für Bevölkerungsbefragungen zu identifizieren.

Schlagwörter: Response-Frequency Measure, Medienselektion, Gewohnheiten, implizite Messung

Funding: The study presented in this paper was funded by Google Germany GmbH. 


\section{Refining the Response-Frequency Measure of Media Habit - The role of time pressure}

Habitual media use is a growing subject in communication research (for an overview see e.g., LaRose, 2010). Research consistently shows that media habits are important determinants of media selection (e.g., Bayer \& Campbell, 2012; Koch, 2010; Naab, 2013; Naab \& Schnauber, 2016; Peters, 2007; Schnauber, 2017). Likewise, media habits are of interest to media practitioners and program planners (Webster, Phalen, $\&$ Lichty, 2006). This gives rise to the question how media habits can be adequately measured. Self-report measures are most prevalent to investigate media exposure, media selection, and related phenomena. A highly valued self-report measure is available to measure habits - the self-report habit index (SRHI; Verplanken \& Orbell, 2003). However, this approach is challenged since habitual media use is not performed fully consciously and may therefore not be easily accessible and articulated validly in a self-report measure (Hefner, Rothmund, Klimmt, \& Gollwitzer, 2011). Based on Verplanken and colleagues' (e.g., Verplanken \& Aarts, 1999; Verplanken, Aarts, van Knippenberg, \& van Knippenberg, 1994) response-frequency measure of habit (RFM), Naab and Schnauber (2016) developed the response-frequency measure of media habit (RFMMH) taking into account the particularities of media use behaviors. The RFM and the RFMMH do not rely on the ability of respondents to identify their habitual behavior and report on repetition, limited awareness, and lack of controllability. Instead, they use an implicit approach by imposing time pressure and measuring the activa- tion of a behavioral script - a basic defining characteristic of a habit - that leads to the initiation of habitual behavior.

Initial research based on a student sample indicates that the RFMMH is a valid and reliable measure of media habits and can complement existing instruments (Naab \& Schnauber, 2016). The present paper recalls the measurement approach of the RFMMH and the defining characteristics of habits on which the RFMMH is based. In its main part, the paper serves as a validation study of the RFMMH and addresses two desiderata of the previous research: First, the paper investigates a possible optimization of the administration: The RFMMH requires spontaneously given answers. This paper will elaborate on the use of time pressure in the RFMMH and test different time pressure levels to ensure script-based responses. Second and related to this, the paper examines the applicability of the RFMMH for a broad sample including various age and education groups to investigate whether the RFMMH is a robust measure across general population samples and whether its applicability to various groups depends on time pressure level.

\section{Defining media habits}

Based on social psychological definitions, communication researchers refer to media habits as automatically initiated behavioral responses stored in mental scripts, which an actor performs in recurrent, familiar situations (e.g., LaRose, 2010; Naab \& Schnauber, 2016). Scripts or behavioral schemata are knowledge structures stored in long-term memory. They develop through repetition and iterative learn- 
ing (e.g., Schnauber-Stockmann \& Naab, 2018). The mental script represents associations of internal and external context features, which reliably co-occurred with a behavioral response and expected outcomes of the behavior in the past (Aarts \& Dijksterhuis, 2000; Abelson, 1981). For example, an individual looks for distraction when at home in the evening and decides to switch on television - which turns out to lead to the desired distraction. After facing the same situation looking for distraction in the evening at home - a couple of times, a script forms connecting 'evening,' 'at home' (external context features, see below), 'looking for distraction' (internal context feature, see below) and 'switching on television' (behavioral response). As most everyday behavior is repeated at least seldom rather than performed only once, individuals hold scripts for numerous behaviors (Strack \& Deutsch, 2004). With extensively repeated activation, these scripts become highly accessible (Bamberg, 1996; Fazio, 1990; Schnauber-Stockmann \& Naab, 2018). In consequence, the perception of typical context features or cues (e.g., 'it's evening, I'm at home, and I'm looking for distraction') may then automatically - that is with little cognitive effort, consciousness, awareness, and controllability (Bargh, 1994) - activate the script and initiate the behavioral response (e.g., 'switching on television'). A habit has formed. In short, habits may be defined as scripts which are automatically accessible.

For a closer understanding of different types of habits, it is necessary to consider which cues trigger habitual behavioral responses. Scripts can be triggered by external as well as internal cues: All context features stored in a script are associated with a behavioral response (Abelson, 1981). External cues triggering media habits are place, time, social surroundings, and further environmental factors (Ji \& Wood, 2007; Verplanken \& Wood, 2006). Internal cues are, for example, moods (Ji \& Wood, 2007). Current habit research has furthermore emphasized the relevance of goals of the individual as internal cues (Aarts \& Dijksterhuis, 2000; Naab, 2013; Schnauber, 2017; Verplanken \& Aarts, 1999; for a critique of this view see e.g., Wood \& Neal, 2007).

Besides considering external as well as internal cues triggering habits, researchers differentiate between general and specific habits.

"In the case of specific habits, the instigation cues that elicit the habitual response are confined to a well-defined and particular situation [...], whereas general habits are under the control of cues that appear in many different situations" (Verplanken \& Aarts, 1999, p. 106; see also Naab \& Schnauber, 2016).

Referring to Abelson (1981), general habits may be conceptualized as metascripts: Formerly separate scripts for various specific situations can contain similar behavioral sequences. For illustrative purposes, one may imagine that these scripts are restructured to form a meta-script. An individual may, for example, always use television when looking for entertainment and form a script associating television use with the internal context cue 'need for entertainment'. The same person may also use television every time when searching for information. This behavioral sequence forms another script associating television use with the context cue 'need for information'. As the behavioral response - television use - in these two scripts is similar, the scripts may be merged into a 
meta-script. All cues stored in the formerly separate scripts, namely looking for entertainment and information, can instigate the meta-script to select television (Abelson, 1981). General habits have a broader scope than specific habits and therefore influence people's everyday lives to a larger extent (Verplanken \& Aarts, 1999).

In addition to the differentiation which internal or external cues trigger a habit and how specific these cues are, habitual media selection can refer to various levels of media choice, among them selection of media devices, content providers, or genres. In its current form, the RFMMH measures media device habits. Media devices, that is television, radio, print newspaper, Internet-equipped computers and mobile devices, represent the 'gateways' for any subsequent intra-media content selection (Webster, 2009; for the idea of gateway habits see Oulasvirta, Rattenbury, Ma, \& Raita, 2012). Today, similar or even the same content is available on various devices. Thus, individuals interested in specific content are not bound to a specific device - they may, for example, either watch their favorite series on television or use their computer or mobile device. Reception and, in consequence, media effects may, however, vary depending on the very device through which content is delivered, for example due to differences in screen sizes (e.g., Lombard, Reich, Grabe, Bracken, \& Ditton, 2000), typical modes of reception (e.g., suitability as a background medium, temporal structures of content provided), or suitability for shared use. Therefore, it is highly relevant to consider media device habits when dealing with media selection.
Compared to other behaviors often researched for their habitual character (e.g., brushing one's teeth, seatbelt use), media device habits are predestinated to be general in nature. Media devices provide a multitude of contents and serve a broad variety of goals (LaRose, 2010; LaRose \& Eastin, 2004; McQuail, 1986; Papacharissi \& Rubin, 2000). Thus, their use is not confined to a narrow set of situations and media use might be an efficient way to gratify many needs. The RFMMH presented in the following focuses on measuring such general media device habits.

\section{Procedure of the Response- Frequency Measure of Media Habit}

The RFMMH is a media-tailored version of the RFM (Verplanken \& Aarts, 1999; Verplanken Aarts, van Knippenberg, \& Moonen, 1998; Verplanken et al., 1994) and measures general media device habits. It is an implicit measure that does not rely on memory and selfreport of past behavior or self-perceived automatism, but on automatically activated associations of a cue with a behavioral response.

In a self-administered online questionnaire, ${ }^{1}$ participants are presented with a variety of cues in form of vignettes and have to spontaneously select a media behavior in response to this vignette. The three important features of the RFMMH are (a) the vignettes, (b) the media devices as response categories, and (c) the procedure to ensure spontaneous answers.

(a) All vignettes used in the current version of the RFMMH refer to goals that can potentially be fulfilled by me-

1 Information on programming the RFMMH is available from the authors upon request. 
dia use. Following the procedure by Naab and Schnauber (2016), participants are presented with 16 vignettes, for example 'You want to have fun' and 'You are bored' (see Table 1). The goal dimensions are mainly derived from gratifications identified in the uses and gratifications literature. They include entertainment, escapism, media-stimulated interpersonal communication, and information (e.g., LaRose \& Eastin, 2004; McQuail, 1986; Papacharissi \& Rubin, 2000). Only goal dimensions are included that can potentially be gratified through the use of different media devices.

Table 1. RFMMH-vignettes - English and German version

\begin{tabular}{|c|c|}
\hline Dimension & Vignette \\
\hline \multirow{4}{*}{ Entertainment } & You want to have fun / Sie wollen Spaß haben \\
\hline & You want to cheer yourself up / Sie möchten sich aufheitern \\
\hline & You want to be excited / Sie möchten etwas Spannendes erleben \\
\hline & You want to be entertained / Sie möchten unterhalten werden \\
\hline \multirow{4}{*}{ Escapism } & You are bored / Ihnen ist langweilig \\
\hline & You want to pass time / Sie möchten sich die Zeit vertreiben \\
\hline & You want to escape your daily routine / Sie möchten dem Alltag entfliehen \\
\hline & You have spare time / Sie haben gerade freie Zeit \\
\hline \multirow{4}{*}{$\begin{array}{l}\text { Media-stimulated } \\
\text { interpersonal } \\
\text { communication }\end{array}$} & $\begin{array}{l}\text { You are looking for topics to talk about / Sie suchen nach Gespräch- } \\
\text { sthemen }\end{array}$ \\
\hline & $\begin{array}{l}\text { You are looking for new stimuli / Sie möchten neue Anregungen } \\
\text { bekommen }\end{array}$ \\
\hline & You are looking for food for thought / Sie wollen Denkanstöße bekommen \\
\hline & You want to join in a conversation / Sie wollen mitreden können \\
\hline \multirow{4}{*}{ Information } & You want to be up to date / Sie möchten auf dem Laufenden bleiben \\
\hline & You want to get some information / Sie möchten sich informieren \\
\hline & You want to learn new things / Sie möchten Neues erfahren \\
\hline & $\begin{array}{l}\text { You are looking for up-to-date information / Sie suchen aktuelle } \\
\text { Informationen }\end{array}$ \\
\hline
\end{tabular}

Note. German RFMMH-vignettes were used. 
Contrary to uses and gratifications research which assumes a rather rational selection process the RFMMH does not require respondents to evaluate whether or not the goals are fulfilled by a given media device (e.g., Palmgreen \& Rayburn, 1982). The RFMMH as an implicit measure uses the goals as vignettes triggering associated behavioral responses, that is media device selection. Respondents indicate which media device is spontaneously associated with the goals on the vignettes. If a media device is highly accessible in various situations, this indicates a general habit of selecting this device. As such, the RFMMH is less sensitive to specifics of the data collection situation. Different from explicit measures, respondents should not and - due to time pressure cannot deliberately consider the most appropriate answer by weighing situational features, but select their habitual option based on their script.

(b) The current version of the RFMMH measures media device habits. These "gateway habits" (Oulasvirta et al., 2012; e.g., the habit of turning on television) represent the starting point for any media use episode. Only media devices a person uses at least seldom are included in the RFMMH response categories for the respective participant. The order of the media devices is randomized between respondents to prevent sequence effects. As the presented goal vignettes do not necessarily result in media use, participants are also given the additional response category "I would do something else".

The RFMMH is a measure of general habits (see above), that is of habits that are not restricted to a specific situation, for example to habitual information seeking. Therefore, it measures the level of invariance in choices of a par- ticipant over all presented goal situations. General habit strength for a media device is indexed by the number of choices of the respective device across the 16 vignettes. For example, the more often a participant chooses television across various vignettes, the stronger is their general television habit.

(c) Respondents are instructed to selecting spontaneously and without further thinking the media device they would choose based on the respective vignette. To enhance the probability of spontaneous answers to the presented cues, time pressure is imposed so respondents are forced to give the answer that comes to their minds first. Imposing time pressure is the most common feature of implicit measures (Hefner et al., 2011). A countdown signals the time left to answer the respective vignette. After respondents made a choice or when they do not answer within the timeframe the online questionnaire automatically switches to the next vignette.

This method is based on the wellproven assumption that reaction time is related to information processing speed as well as accessibility of objects and behavioral responses (Bassili \& Fletcher, 1991). Highly accessible objects can be automatically activated and, in consequence, quickly retrieved from memory (Fazio, 1990). Thus, forcing participants to answer under time pressure "tap[s] on automatic reactions" (Hefner et al., 2011, p. 182). Implicit tests are suitable to measuring habit strength as habits are highly accessible and qualify as automatic reactions to the presence of cues. Supporting the connection between time pressure and retrieving habitual responses, research shows that under circumstances of limited opportunity to elaborate, people rely on es- 
tablished habits or related cognitive shortcuts (Strack \& Deutsch, 2004).

Whereas some implicit tests use reaction time per se as a measure of accessibility, this is not the case for the RFMMH. Instead, time pressure in the RFMMH serves to prevent higher-order cognitive processes and thereby ensures script-based answers. The accumulation of script-based selections of a media device across various goals then indicates a general media device habit.

\section{Current research}

In an initial study $(N=617$, Naab $\&$ Schnauber, 2016), the RFMMH showed satisfactory validity and testretest-reliability for television and computer habits. Furthermore, it correlated significantly with habit strength measured by the established SRHI (Verplanken \& Orbell, 2003). However, at least two aspects remained unclear. First, the level of time pressure allowing respondents to read and answer the vignettes while at the same time being as high as possible to encourage automatic responses was not tested systematically. The RFMMH is based on the assumption that participants report the media device that is automatically instigated by the presented goal on the vignette and do not engage in thoughtful elaboration or give post hoc rationalized answers. Therefore, time pressure is imposed.

In the study by Naab and Schnauber (2016), a pretest $(N=61)$ determined the amount of time pressure: Most vignettes were answered within seven seconds (based on the mean reaction time of $M=5.62 \mathrm{~s}$ and adding one standard deviation of $S D=1.08$ ). This timeframe included the whole process of reading the vignette and choosing an answer. Ac- tual reaction time was well within the provided timeframe $(M=3.46 \mathrm{~s} ; S D=$ 0.69; Naab \& Schnauber, 2016). This leads to the question whether time pressure of seven seconds was too weak and some respondents may have chosen a media device after deliberate elaboration on the presented vignettes. This can lead to flawed results of the RFMMH. Therefore, the present paper will apply different time pressure levels in the administration of the RFMMH and compare the results to identify a preferable time pressure level. It hereby takes three indicators into account: (1) Average reaction time per vignette is an indicator for the actual time needed under different time pressure levels. (2) As the questionnaire automatically switches to the next vignette after the time limit, respondents who would have needed more time cannot respond to a vignette. Therefore, the amount of item non-response to the vignettes is an additional indicator for the ideal amount of time pressure. (3) Habit strength measured by the RFMMH is the third indicator. If it differs depending on time pressure condition, this may indicate a bias due to (possibly) deliberate elaboration in moderate and weak time pressure conditions.

RQ1: How does time pressure level influence reaction time in response to the vignettes?

RQ2: How does time pressure level influence the amount of item nonresponse to the vignettes?

RQ3: Does habit strength measured by the RFMMH differ between time pressure conditions?

Second, the feasibility of the RFMMH for different population groups needs to be assessed as the initial study was conducted with a student sample. The amount of time pressure must be ade- 
quate for heterogeneous samples including respondents with lower cognitive resources. Individual characteristics might limit respondents' ability to react fast enough to produce valid answers within a time limit.

Literature finds evidence for inter-individual differences in cognitive speed. Cognitive power of the brain, working memory, and processing resources are lower for less educated individuals (as a proxy for intelligence) and decline with age (Faust, Balota, Spieler, \& Ferraro, 1999; MacPherson, Phillips, \& Della Sala, 2002; Salthouse, Babcock, \& Shaw, 1991; Zelinski \& Burnight, 1997). This leads to slower information processing. Lower cognitive speed generally results in (or is indicated by) a longer response time (for an overview see Faust et al., 1999). This raises the question whether the time pressure level applied in the RFMMH is adequate for various sociodemographic groups, especially samples with a broad range of age and education levels. Specific groups might face difficulties in higher time pressure conditions. As the RFMMH poses the same time pressure limit on all participants, this would limit the feasibility of the RFMMH for heterogeneous samples.

RQ4: Do age and education level interact with time pressure level in their influence on (a) reaction time to the vignettes, (b) the amount of item non-response to the vignettes, (c) and habit strength measured by the RFMMH?

\section{Method}

The study tested different time pressure conditions as part of a project funded by Google Germany GmbH on the habitual use of the Internet.

\subsection{Sample and procedure}

A disproportional quota sample was drawn from an online access panel. In terms of gender, age, and education, the sample was evenly split: In total, 1,849 participants were included in the subsequent analyses $(50 \%$ male; $33 \%$ 18 to 29 years, $32 \% 30$ to 49 years, and $35 \% 50$ years or older; $51 \%$ low in education). In a between-subject experimental design, the amount of time pressure was varied in nine conditions. Time pressure levels started from four seconds and went up to eleven seconds. Four seconds was chosen as a starting point as respondents had to read the vignettes prior to choosing the answer, and reading takes some time. Based on the average response time in the initial study $(M=3.46 \mathrm{~s}$; $S D=0.69$ ) as well as qualitative feedback of respondents on the felt amount of time pressure, higher time pressure seemed not feasible. Additionally, no time pressure was imposed in one condition. Respondents were randomly assigned to one of the nine conditions ( $n$ between 194 and 214).

\subsection{Measures}

RFMMH. The procedure closely followed the description of Naab and Schnauber (2016; see 'Procedure of the Response-Frequency Measure of Media Habit'). As described, time pressure varied between conditions. Response categories were television, radio, (print) newspaper, (print) magazine, Internet (via smartphone, tablet, laptop, netbook, or desktop PC). Respondents were instructed to consider their media device use (e.g., "If you listen to the radio via a radio set, please choose 'radio'; if you use web-radio via smart- 
Table 2. Reaction times per vignette between time pressure conditions

\begin{tabular}{lll}
\hline & $M$ & SD \\
\hline $4 \mathrm{~s}$ & $2.38^{\mathrm{a}}$ & 0.53 \\
\hline $5 \mathrm{~s}$ & $2.62^{\mathrm{b}}$ & 0.60 \\
\hline $6 \mathrm{~s}$ & $2.81^{\mathrm{c}}$ & 0.69 \\
\hline $7 \mathrm{~s}$ & $2.90^{\mathrm{cd}}$ & 0.78 \\
\hline $8 \mathrm{~s}$ & $2.97^{\mathrm{cd}}$ & 0.90 \\
\hline $9 \mathrm{~s}$ & $3.16^{\mathrm{d}}$ & 0.90 \\
\hline $10 \mathrm{~s}$ & $3.02^{\mathrm{cd}}$ & 0.90 \\
\hline $11 \mathrm{~s}$ & $2.93^{\mathrm{cd}}$ & 0.89 \\
\hline No limit & $2.94^{\mathrm{cd}}$ & 1.06 \\
\hline
\end{tabular}

Note. $F(8 / 1840)=16.19, p<.001, \eta^{2}=.066$; values with different superscripts differ significantly (Tamhane).

phone, tablet, laptop, netbook, or desktop PC, please choose 'Internet'”). Additionally, the option "I would do something else" was provided. The following analyses consider habit strength for television $(M=3.54, S D=2.63$, $M d n=3.00, \operatorname{Min}=0.00, \operatorname{Max}=16.00)$ and Internet $(M=8.03, S D=0.55$, $M d n=8.00$, Min $=0.00, \operatorname{Max}=16.00)$.

Socio-demographics. Respondents' gender, age, and education level were assessed.

\section{Results}

\subsection{Differences in reaction time, item non-response, and habit strength between time pressure conditions}

Table 2 summarizes the average reaction times per vignette within the different time pressure conditions (RQ1). The average reaction times in the four- and five-seconds conditions differed significantly from the reaction times in the other time pressure conditions. However, above five seconds, the average reaction times did not change - with one exception (six vs. nine seconds) - any- more. In all conditions, the questionnaire automatically switched to the next vignette when either the time limit was reached or an answer was given. Thus, the maximum time respondents could spend on a vignette depended on the condition. Therefore, higher levels of time pressure of course result in lower reaction times. Still, the comparison of the time spent on each vignette contains valuable information on a possible threshold: If the actual time spent on a vignette does not differ between conditions, the imposed time pressure level does not change the time taken to answer a vignette and differences in the measurement are not to be expected.

To make further analyses more parsimonious, time pressure conditions were grouped as follows: four seconds, five seconds, six seconds, seven seconds, eight to eleven seconds, no time limit.

The number of vignettes not answered differed between the six time pressure groups (RQ2). The four seconds condition produced most item non-response $(45 \%$ of the respondents skipped at least one vignette, $M=1.00$, 
$S D=1.95)$. The five seconds condition performed significantly better $(26 \%$ of the respondents skipped at least one vignette, $M=0.46, S D=1.08)$. Within the six seconds condition, $17 \%$ skipped at least one vignette $(M=0.30$, $S D=0.86)$. Less than ten percent of the participants skipped one vignette or more in the other conditions ( $M$ between 0.08 and 0.15 ; $S D$ between 0.43 and $1.07 ; \chi^{2}(5)=277.57, p<.001$, Cramér's $V=.387$ ).

Finally, the influence of the different time pressure conditions on television and Internet habit strength was assessed (RQ3). Habit strength measured by the RFMMH did not differ significantly between time pressure conditions (television: $F(5 / 1805)=0.50$, $p=.774, \eta^{2}=.001$; Internet: $\left.F(5 / 1848)=0.88, p=.496, \eta^{2}=.002\right)$.

\subsection{Influences of age and education level}

To test whether specific socio-demographic groups differed in their ability to complete the RFMMH in different time pressure conditions (RQ4), we first focus on the reaction time needed to answer the RFMMH vignettes. We conducted a multiple regression analysis with the average reaction time per vignette as dependent variable and age and education level $($ low $=0)$ as independent variables. Additionally, we controlled for time pressure condition (in s) to account for the effect of the provided time limit $\left(R_{\text {adj. }}^{2}=.07\right.$; $F(5 / 1838)=26.49, p<.001$; $N=1849$ ). Education level did not influence reaction time $(b=0.00$; $s e=0.04 ; t=0.03 ; p=.975)$. Age had a significant impact $(b=0.01$; $s e=0.00 ; t=7.85 ; p<.001)$ : Older respondents took longer to complete the RFMMH. The effect size, however, was rather small $(\beta=.18)$. To answer RQ4a, that is to test whether respondent groups differed in their ability to cope with higher time pressure, interaction terms between socio-demographics and time pressure condition were included in the regression. No interaction term was significant (time pressure condition $\mathrm{X}$ age: $b=0.00$; $s e=0.00 ; t=1.59$; $p=.112$; time pressure condition $\mathrm{X}$ education level: $b=-0.02 ;$ se $=0.01 ; t=-1.14$; $p=.253)$. Thus, all respondent groups were equally able to cope with higher time pressure.

Second, we conducted a logistic regres$\operatorname{sion}^{2}$ to test whether elderly or less educated respondents are more likely to produce item non-response (dependent variable: $0=$ no item non-response, 1 = at least one vignette not answered; independent variables: education level $(0=$ low $)$ and age; additional control variable: time pressure condition (in s); Nagelkerke's $R^{2}=.22 ; X^{2}(5)=226.26$, $p<.001, N=1849)$. Unlike education level $(\operatorname{Exp}(B)=1.02, W=0.03$; $p=.872)$ age was a significant predictor of item non-response in the RFMMH $(\operatorname{Exp}(B)=1.02, W=18.73$; $p<.001)$ : Older respondents tended to produce item non-response. The effect, however, was small. The interaction term serves to answer RQ4b: The interactions between socio-demographics and time pressure condition were not significant (time pressure condition $\mathrm{X}$ age: $\operatorname{Exp}(B)=1.00, W=2.78$; $p=.096$; time pressure condition $\mathrm{X}$ ed-

2 Due to the distribution of the number of vignettes - not answered $-87 \%$ of the respondents answered all vignettes a linear regression model did not fit the data. 
ucation level: $\operatorname{Exp}(B)=1.04, W=0.23$; $p=.630)$. The higher likelihood of older respondents to produce item non-response was thus not dependent on different time pressure levels.

Third, the influence of the different time pressure conditions on general habit strength measured by the RFMMH for the respondent groups was evaluated. We conducted multiple regression analyses with general habit strength measured by the RFMMH for television $\left(R_{\text {adj }}^{2}=.01 ; F(5 / 1795)=\right.$ $4.66, p<.001 ; N=1806)$ and Internet $\left(R^{2}=.05 ; F(5 / 1838)=19.14, p<.001\right.$; $N=1849$ ) as dependent variables. Independent variables were education level $(0=$ low $)$ and age as well as time pressure condition (in s) as control variable. Compared to younger respondents, older participants show stronger general television habits $(b=0.02 ;$ se $=0.00 ; t=4.07$; $p<.001)$, but weaker general Internet habits $(b=-0.05$; $s e=0.01 ; t=9.35$; $p<.001)$. Whereas general television habits did not differ between education levels $(b=-0.20$, se $=0.12$; $t=-1.65 ; p=.100)$, higher educated respondents showed stronger general Internet habits $(b=0.45$, se $=0.17$; $t=2.71 ; p=.007)$. However, only the interaction terms between time pressure condition and the socio-demographics indicate whether respondent groups differ in their measured general habit strength depending on the respective time pressure condition (RQ4c). The interactions between socio-demographics and time pressure condition for general television habits (time pressure condition $\mathrm{X}$ age: $b=$ $0.00 ; s e=0.00 ; t=1.29 ; p=.197$; time pressure condition $\mathrm{X}$ education level: $b=0.03 ; s e=0.05 ; t=0.68 ; p=.498)$ and general Internet habits (time pres- sure condition $\mathrm{X}$ age: $b=0.00$; $s e=0.00 ; t=1.16 ; p=.245$; time pressure condition $\mathrm{X}$ education level: $b=0.11 ; s e=0.06 ; t=1.75 ; p=.080$ ) were not significant. We interpret this as a strong hint that general media device habit strength measured by the RFMMH was not influenced by the time pressure condition for any of the socio-demographic groups.

\section{Discussion}

The role of habit strength in media selection receives growing attention in communication research. Various studies have shown that habits are important predictors of media activities (e.g., Bayer \& Campbell, 2012; Koch, 2010; Naab, 2013; Naab \& Schnauber, 2016; Peters, 2007; Schnauber, 2017). Therefore, valid and economic measures of habit strength applicable to samples with different levels of cognitive ability are needed. Recently, Naab and Schnauber (2016) introduced the response-frequency measure of media habit (RFMMH) to communication research, which measures general goalrelated media device habits.

The current validation study showed that education level did not influence the ability to complete the RFMMH. Older respondents showed a slightly higher reaction time and a higher probability of item non-response. The differences, however, were small and indicate that elderly people are still well able to complete the RFMMH independently of time pressure level. This suggests that the RFMMH can be used in studies with heterogeneous samples.

Results on the appropriate amount of time pressure were less clear: General media device habit strength meas- 
ured by the RFMMH did not differ significantly between time pressure conditions - including the condition without time pressure. This suggests that actual time pressure is not as crucial as expected, but rather the instruction to answer spontaneously is sufficient to induce quick, non-deliberate, script-based answers (in an online questionnaire). We argue, however, that time pressure should still be used as it ensures fast administration and prevents more deliberate processes. When deciding on an ideal amount of time pressure for participants across various age and education levels, five seconds seem to be the best choice. Above five seconds, reaction time did not change, indicated by the fact that reaction time under lower time pressure did not differ from reaction time under no time pressure. Compared to four seconds, the five seconds condition allowed more respondents to read and answer all vignettes, showing that for some participants, four seconds were too short to complete the RFMMH. This especially seems to apply to elderly respondents who took slightly longer to complete the RFMMH. To allow this population group to complete the RFMMH as well, five seconds seem feasible as the universal time pressure level. Thus, it will not be necessary to introduce different time pressure levels for sub-samples differing in cognitive speed.

\section{Limitations and potential adaptions of the RFMMH}

The RFMMH in its current form is designed to measure general, goal-related media device habits. The RFMMH is not designed to measure specific hab- its, that is automatic behavioral responses that are associated with a quite particular range of gratifications sought. However, the goal-related vignettes used in the present version of the RFMMH may be adapted to capture more specific habits, for example with vignettes presenting various goals related to searching information (e.g., surveillance information, weather news, information about social affairs). In a similar way, the vignettes could be adapted to measure the dependence of habitual media selection on external situational factors like media choice in various spatial and social surroundings. Such adaptions would require additional pretesting to identify adequate vignettes as the respective cues should provide the potential to be fulfilled by all response categories (that is media behaviors). For example, mere spatial cues like "at home", "on the road", "at work" as vignettes for media device selection would be problematic as they favor mobile over stationary devices due to different accessibility.

Furthermore, the current version of RFMMH focuses on media device habits. Whereas media device selection initiates a media use episode, subsequent steps in the media selection process may also be habit-driven, for example the selection of media genre or content. Here again, pretesting of suitable vignettes to adapt the RFMMH to these selections steps is needed and may be a subject to future research.

The RFMMH allows participants to pick only one device upon each vignette. This follows the idea that habitual associations relieve from the burden of weighing - even a small number of - behavioral responses. However, it is possible that specific situations or cues are associated with 
more than one behavioral response (Fiske \& Taylor, 1991). The strength of these associations may vary, however, while a stronger association indicates higher habit strength for the respective behavioral response (Fazio, 1990). To account for these multiple associations, the RFMMH could allow for choosing more than one response category per vignette. Klöckner and colleagues (2003) have tested a response-frequency measure of habitual travel mode choice allowing such multiple choices of travel modes. They conclude that the results of the multiple-choice RFM barely differ from a single-choice RFM and it is less efficient.

Finally, our response categories may be conceptually confusing as we compare "Internet" to television (as well as radio, newspaper, and magazine). Whereas the latter clearly are devices, the former may be used on a variety of devices. Although respondents were instructed on choosing "Internet" when referring to devices like smartphone, tablet, laptop, netbook, or desktop PC, we recommend to be conceptually more specific in the future and provide these devices (or a selection thereof) as response categories.

\section{Conclusion}

In conclusion, the current study indicates that the RFMMH is a measure worth considering in a broad range of audience studies with heterogeneous samples. In contrast to existing self-report measures, the RFMMH focuses on automatic script-based initiation of a behavior, which is the core of the habit construct. Furthermore, the application of the RFMMH is economic. Its administration proceeds fast. Additionally, it differs from common psy- chological scale measures. This might be beneficial to the perception of a survey by the respondents as being rich in variety. Thus, the RFMMH can complement existing habit measures, which jointly provide a more complete picture of the genuine role of habit strength in media use. Furthermore acknowledging that media habits play a decisive role in media selection processes, the RFMMH as a fast-to-administer habit measure may be used in a wide variety of studies on media choice, allowing to reliably and validly control for the influence of habits.

\section{References}

Aarts, H., \& Dijksterhuis, A. (2000). Habits as knowledge structures: Automaticity in goal-directed behavior. Journal of Personality and Social Psychology, 78(1), 53-63. https://doi.org/10.1037/0022 3514.78.1.53

Abelson, R. P. (1981). The psychological status of the script concept. American Psychologist, 36(7), 715-729. https://doi. org/10.1037/0003-066X.36.7.715

Bamberg, S. (1996). Habitualisierte PKWNutzung: Integration des Konstrukts "Habit" in die Theorie des geplanten Verhaltens [Habitual car use: Integration of the construct "habits" into the theory of planned behavior]. Zeitschrift für Sozialpsychologie, 27(4), 295-310.

Bargh, J. A. (1994). The four horsemen of automaticity: Awareness, intention, efficiency and control in social cognition. In R. S. Wyer, \& T. K. Srull (Eds.), Handbook of social cognition (Vol. 1, pp. 1-40). Hillsdale, NJ: Erlbaum.

Bassili, J. N., \& Fletcher, J. F. (1991). Response-time measurement in survey research. A method for CATI and a new look at nonattitudes. Public Opinion 
Quarterly, 55(3), 331. https://doi. org/10.1086/269265

Bayer, J. B., \& Campbell, S. W. (2012). Texting while driving on automatic: Considering the frequency-independent side of habit. Computers in Human Behavior, 28(6), 2083-2090. https://doi.org/10.1016/j. chb.2012.06.012

Faust, M. E., Balota, D. A., Spieler, D. H., \& Ferraro, F. R. (1999). Individual differences in information-processing rate and amount: Implications for group differences in response latency. Psychological Bulletin, 125(6), 777-799. https://doi. org/10.1037/0033-2909.125.6.777

Fazio, R. H. (1990). Multiple processes by which attitudes guide behavior: The mode model as an integrative framework. Advances in Experimental Social Psychology, 23, 75-109. https://doi.org/10.1016/ s0065-2601(08)60318-4

Fiske, S. T., \& Taylor, S. E. (1991). Social cognition (2nd). New York: McGraw-Hill.

Hefner, D., Rothmund, T., Klimmt, C., \& Gollwitzer, M. (2011). Implicit measures and media effects research: Challenges and opportunities. Communication Methods and Measures, 5(3), 181-202. https:// doi.org/10.1080/19312458.2011.597006

Ji, M. F., \& Wood, W. (2007). Purchase and consumption habits: Not necessarily what you intend. Journal of Consumer Psychology, 17(4), 261-276. https://doi. org/10.1080/10577400701542403

Klöckner, C., Matthies, E., \& Hunecke, M. (2003). Problems of operationalizing habits and integrating habits in normative decision-making models. Journal of Applied Social Psychology, 33(2), 396-417. https://doi.org/10.1111/j.1559-1816.2003. tb01902.x

Koch, T. (2010). Macht der Gewohnheit? Der Einfluss der Habitualisierung auf die Fernsehnutzung [Power of habit? The influence of habitualization on television use]. Wiesbaden, Germany: VS.
LaRose, R. (2010). The problem of media habits. Communication Theory, 20(2), 194-222. https://doi.org/10.1111/j.14682885.2010.01360.x

LaRose, R., \& Eastin, M. S. (2004). A social cognitive theory of Internet uses and gratifications: Toward a new model of media attendance. Journal of Broadcasting \& Electronic Media, 48(3), 358-377. h t t p s://doi.org/10.1207/ s15506878jobem4803_2

Lombard, M., Reich, R. D., Grabe, M. E., Bracken, C. C., \& Ditton, T. B. (2000). Presence and television: The role of screen size. Human Communication Research, 26(1), 75-98. https://doi.org/10.1111/ j.1468-2958.2000.tb00750.x

MacPherson, S. E., Phillips, L. H., \& Della Sala, S. (2002). Age, executive function and social decision making: A dorsolateral prefrontal theory of cognitive aging. Psychology and Aging, 17(4), 598-609. https://doi.org/10.1037/0882-7974.17.4.598

McQuail, D. (1986). Mass communication theory. An introduction. London, UK: Sage

Naab, T. K., \& Schnauber, A. (2016). Habitual initiation of media use and a responsefrequency measure for its examination. Media Psychology, 19(1), 126-155. https:// doi.org/10.1080/15213269.2014.951055

Naab, T. K. (2013). Gewohnheiten und Rituale der Fernsehnutzung. Theoretische Konzeption und methodische Perspektiven [Habits and rituals of television viewing. Theoretical conception and methodological perspectives]. Baden-Baden, Germany: Nomos.

Oulasvirta, A., Rattenbury, T., Ma, L., \& Raita, E. (2012). Habits make smartphone use more pervasive. Personal and Ubiquitous Computing, 16(1), 105-114. https://doi.org/10.1007/s00779-0110412-2

Palmgreen, P., \& Rayburn, J. D. (1982). Gratification sought and media exposure: 
An expectancy value model. Communication Research, 9(4), 561-580. https://doi.org/10.1177/00936508 2009004004

Papacharissi, Z., \& Rubin, A. M. (2000). Predictors of internet use. Journal of Broadcasting \& Electronic Media, 44(2), 175-196. https://doi.org/10.1207/ s15506878jobem4402_2

Peters, O. (2007). Social psychological determinants of mobile communication technology use and adoption ( $\mathrm{PhD}$ thesis). University of Twente, Enschede. Retrieved from http://doc.utwente.nl/58107/1/thesis_Peters.pdf

Salthouse, T. A., Babcock, R. L., \& Shaw, R. J. (1991). Effects of adult age on structural and operational capacities in working memory. Psychology and Aging, 6(1), 118-127. https://doi.org/10.1037/08827974.6.1.118

Schnauber-Stockmann, A. \& Naab, T. K. (2018). The process of forming a mobile media habit: results of a longitudinal study in a real-world setting. Media Psychology. Advance online publication. https://doi.org//10.1080/15213269.2018. 1513850

Schnauber, A. (2017). Medienselektion im Alltag: Die Rolle von Gewohnheiten im Selektionsprozess [Media selection in everyday life: The role of habits in media selection processes]. Wiesbaden, Germany: Springer VS.

Strack, F., \& Deutsch, R. (2004). Reflective and impulsive determinants of social behavior. Personality and Social Psychology Review, 8(3), 220-247. https://doi. org/10.1207/s15327957pspr0803_1

Verplanken, B., \& Aarts, H. (1999). Habit, attitude, and planned behaviour: Is habit an empty construct or an interesting case of goal-directed automaticity? European Review of Social Psychology, 10(1), 101134. https://doi.org/10.1080/14792 779943000035
Verplanken, B., Aarts, H., van Knippenberg, A., \& Moonen, A. (1998). Habit versus planned behaviour: A field experiment. British Journal of Social Psychology, 37(1), 111-128. https://doi.org/10.1111/ j.2044-8309.1998.tb01160.x

Verplanken, B., Aarts, H., van Knippenberg, A., \& van Knippenberg, C. (1994). Attitude versus general habit: Antecedents of travel mode choice. Journal of Applied Social Psychology, 24(4), 285-300. https://doi.org/10.1111/j.1559-1816. 1994.tb00583.x

Verplanken, B., \& Orbell, S. (2003). Reflections on past behavior: A self-report index of habit strength. Journal of Applied Social Psychology, 33(6), 1313-1330. https://doi.org/10.1111/j.1559-1816.2003. tb01951.x

Verplanken, B., \& Wood, W. (2006). Interventions to break and create consumer habits. Journal of Public Policy o Marketing, 25(1), 90-103. https://doi.org/10.1509/ jppm.25.1.90

Webster, J. G. (2009). The role of structure in media choice. In T. Hartmann (Ed.), Media choice. A theoretical and empirical overview (pp. 221-233). New York: Routledge.

Webster, J. G., Phalen, P. F., \& Lichty, L. W. (2006). Ratings analysis: The theory and practice of audience research. Mahwah, NJ: Lawrence Erlbaum.

Wood, W., \& Neal, D. T. (2007). A new look at habits and the habit-goal interface. Psychological Review, 114(4), 843-863. http s:// d o i.org/10.1037/0033295X.114.4.843

Zelinski, E. M., \& Burnight, K. P. (1997). Sixteen-year longitudinal and time lag changes in memory and cognition in older adults. Psychology and Aging, 12(3), 503513. https://doi.org/10.1037/08827974.12.3.503 